\title{
7) Armado y desarmado de una confederación: el liderazgo de ¿ Calfucurá en el período de la organización nacional ${ }^{1}$
}

Ingrid de Jong ${ }^{2}$

\section{Introducción}

En La conquista de 15.000 leguas, obra publicada en las vísperas Ede la preparación de las campañas militares que constituirían la Ilamada "Conquista del Desierto", Estanislao Zeballos ([1878] 1958) intentó compendiar los principales conocimientos acerca de las características geográficas, históricas y poblacionales de los territorios pampeano-patagónicos próximos a ser conquistados. Un capítulo de esta obra fue dedicado a describir "la índole y los elementos de las poblaciones indígenas, sobre las cuales va a operar el ejército de la nación" y "discurrir sobre la actitud que asumirán los indios en presencia del ejército expedicionario" (1958:323). Entre los principales grupos que todavía conservaban su poder en el "desierto", Zeballos presenta a los cacicazgos de Salinas Grandes y Leuvucó como los dos grandes "imperios indígenas" en que se dividía la Pampa: desmembraciones de la "belicosa familia araucana", los "chadiches" y "ranquelches" reconocen como jefes supremos a Namuncurá y Epumer, herederos de las "dinastías" de los Curá y de los Rosas. Estos "emperadores" fundarían su ascendencia en el prestigio conferido por la pertenencia a estas "familias reinantes", poseedoras de las "virtudes de la valentía, la criminalidad y la borrachera", apreciadas por los pueblos indígenas como "derecho divino" (1958:307). También identifica otros sectores que no forman parte de estos imperios. Algunos no pasan de constituir

1 Una primera versión del presente trabajo fue presentada al Simposio “Liderazgo Indígena en las fronteras americanas", realizado el 2 y 3 de agosto de 2007 en el Museo Etnográfico de la Facultad deFilosofía y Letras de la Universidad de BuenosAires.

2 UBA/CONICET, e-mail: ildejong@hotmail.com 
Ingrid deJ ong

grupos pequeños y móviles que hacen sus propios negocios aprovechando cualquier ocasión para invadir las fronteras. O tros, como el liderado por Pincén, representan la vía elegida por algunos caciques para constituir su propia fuerza, independiente de los soberanos salineros y ranqueles.

En este bosquejo del panorama político indígena, otros grupos se consideran como una amenaza menor, ya por su "índole humanitaria" y su "aptitud para la civilización" como por mantener tratos pacíficos y relaciones comerciales estables con las jurisdicciones de frontera. Estos son los "tehuelches", que "derramarían su sangre en defensa de la colonia del Chubut y de Carmen de Patagones con el mismo entusiasmo y convicción con que nosotros defendemos las fronteras" (1958:323). Pero Zeballos destaca especialmente a Sayhueque como "un aliado importantísimo, que cooperará a la consolidación de los intereses argentinos en el río Negro". Jefe supremo del Gobierno de las Manzanas, sería en la Patagonia el cacique más poderoso, "pues lo aclaman jefe las cinco naciones que pueblan aquellas comarcas que son: los M anzaneros, Picunches, Mapuches, Huilliches y Tehuelches" (1958:319). Para ilustrar la actitud de estos grupos, Zeballos cita las declaraciones atribuidas al cacique por el viajero George Musters y también por Francisco Moreno en sus relatos sobre la visita a las tolderías de los manzaneros en 1870 y 1876, quienes testimonian la continuidad de la decisión de estas agrupaciones de distanciarse de la confrontación que mantenida por Calfucurá con el gobierno desde los inicios de la década de 1870, con el objetivo de preservar sus relaciones pacíficas y defender las fuentes de raciones y comercio con Patagones.

Aunque atendiendo a la necesidad de configurar una imagen estereotipada del "enemigo", en esta descripción del "mapa" político indígena Zeballos repara involuntariamente en el peso adquirido por las relaciones con el estado en el desigual posicionamiento de la población indígena ante el avance militar en los momentos finales del dominio de sus territorios, aspecto relegado por las investigaciones posteriores a estos primeros ensayos de historización. G ran parte de los trabajos de la primera mitad del siglo XX tendió a interpretar las relaciones de frontera enfatizando el conflicto entre sociedades cultural y políticamente polarizadas, reproduciendo, aún en aquellos casos en que se intentaba discutir el carácter salvaje de la naturaleza del indio y cuestionar las prácticas de avance territorial de los gobier- 
nos, una imagen de homogeneidad interna de la sociedad indígena que dejó de lado la preocupación por la dinámica de sus decisiones y acciones políticas. En este marco, la preeminencia del estudio de ciertas figuras, líderes o "héroes" indígenas fue paralela a la tendencia a superponer estos liderazgos por sobre las categorías étnicas derivadas de los nombres utilizados frecuentemente en las fuentes militares, reproduciendo así una percepción del mapa político y étnico indígena en base a unidades prácticamente naturalizadas y estables en el tiempo (de Jong 2007b).

La "Confederación Indígena del cacique Calfucurá" es uno de los ejemplos paradigmáticos de la persistencia de las representaciones consolidadas a fines del siglo XIX. O bjeto de varias reconstrucciones historiográficas ${ }^{3}$, el liderazgo de este jefe se presenta como el referente de la mayor y más permanente concentración de poder en el mundo indígena. Poseedor de una estrategia y capacidad políticas excepcionales, ha sido caracterizado como el exponente y vocero político de la unidad indígena ${ }^{4}$, atribuyéndosele un pleno dominio sobre largos períodos entre los indígenas de Pampa y Patagonia.

Esta interpretación forma parte incluso de trabajos relativamente recientes, en los que Calfucurá es considerado como líder de un poderoso "imperio de la pampa" (Jones 1989, 1999) que se extiende por más de tres décadas a lo largo del siglo XIX. La Confederación Indígena de Calfucurá habría expresado, según esta autora, la centralización y consolidación de que era capaz el gobierno indígena, respondiendo a las necesidades de una mejor organización de sus empresas militares de obtención de ganado. Jones extiende la imagen de este "imperio de la pampa" desde fines del gobierno de Rosas hasta las vísperas de la derrota de Namuncurá (hijo y heredero principal de Calfucurá), situando el resquebrajamiento de la resistencia y de Confederación

3 Para una revisión sobre el modo en que la historiografia ha abordado la figura de Calfucurá remitimos al trabajo de Pérez (2007).

4 No ha dejado de influir en esta construcción el propio discurso de Calfucurá, retomado por diversas fuentes, que frecuentemente se organizó desde el eje de la uni dad pol ítica, territorial y cultural indígena en contraste con los "blancos" o "cristianos". Su discurso de unidad se basaba en elementos legitimadores como el parentesco, la voluntad de un dios superior que orientaba su liderazgo y la preocupación que todo jefe debía tener por el bienestar de sus seguidores y sus familias. La construcción desu liderazgo seorientó no pocas veces a reunir el consenso de las diversas parcial idades políticas de la Pampa y norpatagonia, y sus argumentos enfatizaron la necesi dad de impedir en forma conjunta el avance blanco sobre las tierras indígenas (Avendaño 1999; Hux 1991; Bechis 1999). 
Ingrid deJ ong

Indígena en el contexto de las acciones nacionales de ocupación territorial de 1878 y 1879.

Con una visión diferente, Bechis plantea que la Confederación de Calfucurá constituyó un fenómeno limitado por la segmentalidad de la organización política indígena y que la misma habría comenzado a declinar al poco tiempo de su formación. Así, el cacique salinero habría intentado "una unidad que en realidad nunca existió sino como ficción en cortos períodos cuando hombres como el mismo Calfucurá tenían la sagacidad de encontrar la oportunidad y el poder de convocatoria como para unir las voluntades que su propia organización social dividía" (1999:13). Entre otras razones, que tendrían que ver con los límites de este tipo de sociedades - en las que no había una división del trabajo que permitiera mantener a un sector dedicado exclusivamente a la guerra- para sostener un estado de confrontación militar durante mucho tiempo, sumado a otros factores, como las limitaciones climáticas dadas por las características semi-áridas del ecosistema pampeano-patagónico, la autora otorga un lugar importante al carácter segmental de la sociedad indígena, cuya persistencia habría impedido la permanencia tanto de éste como de otros intentos previos de organización centralizada en la población indígena (Bechis 1989, 1999).

En trabajos recientes (de Jong 2007a; de Jong y Ratto 2008), hemos apuntado a reconstruir la dinámica del liderazgo de Calfucurá diferenciando los contextos y alcances de la llamada "Confederación Indígena" - es decir, de la confederación de fuerzas indígenas que podía ser convocada y movilizada por Calfucurá en determinadas coyunturas- de lo que fue su "cacicazgo", entendido como una relación más estable de autoridad de este jefe por sobre los seguidores que constituirían su propia "unidad política". Dicha distinción nos fue útil no sólo para relativizar aquellas interpretaciones que otorgaban a Calfucurá una capacidad de convocatoria permanente sobre gran parte del espectro indígena sino para aproximarnos a las coyunturas en las que este líder apelaba a la acción conjunta por parte de grupos o parcialidades independientes de la suya. Pero especialmente para identificar un paulatino proceso de angostamiento de esta convocatoria que no puede entenderse únicamente en base a las características segmentales de la organización indígena, sino a los efectos de la política estatal que va configurándose desde finales de la década de 1850.

En este sentido, creemos que el llamado período de la "organización nacional" (Bechis 2002) o "consolidación estatal" (O szlak 2004), 
en el que el estado argentino atraviesa un proceso de creciente unificación política e institucional, presenta características específicas para las relaciones entre el estado y la sociedad indígena, en el que la sistematización de los tratados de paz como dispositivos diplomáticos de la política estatal incrementará su capacidad de ordenar y condicionar el comportamiento político indígena, particularizando los posicionamientos de sus líderes y fragmentando progresivamente aquellas potencialidades para la alianza que se habían expresado en la Confederación Indígena comandada por Calfucurá a mediados de la década de 1850. Siguiendo este planteo, intentaremos reconstruir aquí las dinámicas de las alianzas asumidas por Calfucurá con otros sectores del espectro indígena a lo largo de la segunda mitad del siglo XIX, enfocando en las formas en que las relaciones con el estado condicionaron su convocatoria sobre otros grupos. Esta propuesta, centrada en los efectos de los dispositivos de poder estatales, pretende aportar un aspecto que creemos significativo para la comprensión de las transformaciones de la organización política indígena pampeano patagónica a lo largo del siglo XIX, tema que ha sido objeto de distintas propuestas, no siempre coincidentes.

\section{Las unidades políticas indígenas de Pampa y Patagonia en la segunda mitad del siglo XIX}

Los aportes realizados en las últimas tres décadas desde la historia y la antropología al estudio de las relaciones blanco-indígenas en las regiones de Pampa y Patagonia han abierto el espacio para la comprensión de una historia indígena que había sido minimizada por los estudios de la etnología clásica. En contraposición a un paisaje étnico naturalizado y descontextualizado de los procesos históricos de contacto y dominación, en el que las etnias se configuraban como unidades cultural y racialmente discretas y permanentes en el tiempo, estas investigaciones han contribuido a reconstruir las dinámicas de la población indígena en función de sus relaciones con los gobiernos coloniales y republicanos. Ya en 1981 León Solís proponía la denominación de "territorio indio" al referirse al marco espacial conformado por las pampas y la Araucanía, dentro del cual era posible comprender los vínculos entre grupos indígenas de ambos lados de la cordillera y sus transformaciones en función de los procesos de confrontación y negociación indígenas con los estados coloniales y republicanos (León Solís 1981). La atención prestada 
Ingrid deJ ong

a los intercambios comerciales, los flujos migratorios e influencias culturales vertebrados por los Andes condujeron a incorporar a las poblaciones indígenas como actores de un "espacio fronterizo" que a lo largo de más de tres siglos articuló a la región del Plata y el sur chileno como dos polos de desarrollo capitalista a ambos lados de la cordillera (León Solís 1991; Mandrini 1991; Bandieri 1996; Pinto Rodríguez 1996). Trabajos pioneros como los de Bechis y Palermo sostuvieron el "área arauco-pampeano-patagónica" como unidad desde la cual comprender las interrelaciones internas al mundo indígena (Bechis 1989) cuya articulación con los mercados de Chile y Argentina la convertiría en parte de un "sistema" de carácter "poliétnico y policéntrico" (Palermo 1999). Asimismo, en un aporte fundamental para la comprensión de las conductas indígenas en su relación con las sociedades estatales, Bechis (1989) sentó las primeras interpretaciones de la organización política indígena como una estructura segmental ${ }^{5}$, caracterizando la ascendencia de los caciques indígenas sobre sus seguidores en términos de "autoridad" en contraposición al "poder"6. El carácter no coercitivo de los cacicazgos dotaba a estos vínculos de una capacidad flexible de fisión y fusión constantes, limitando la conformación de estructuras jerarquizadas de poder. La comprensión del carácter consensual de los cacicazgos y de la flexibilidad propia de la organización política indígena contribuyó a romper la imagen de unidades políticas fijas y esenciales, así como a relativizar una concepción del poder de ciertos caciques que algunas fuentes del siglo XIX Ilegaron a concebir bajo términos como "imperios" y "dinastías" (Zeballos [1878] 1958).

Sin embargo, el énfasis puesto en quebrar el aislamiento que tradicionalmente había excluido a los indígenas de la historia social y económica en estos espacios restó atención, al menos hasta hace poco, a la visualización de las heterogeneidades y procesos específicos dentro del mundo indígena. No pocas veces se atribuyó a estas poblaciones un proyecto político común, centrado en preservar "a sangre y fuego" la autonomía política y territorial frente a los intentos de avance blanco, sumado a un desprecio común por la cultura hispana (Palermo 1999).

5 Según Bechis (1989) y basándose en Middleton, la estructura política segmental alude a una configuración política formada por la repetición o fisión de unidades o segmentos autosuficientes más pequeños que la sociedad sin que haya una estructura política superior que los contenga.

6 Bechis toma esta distinción deFried para quien "autoridad se refiere a la habilidad de canalizar la conducta de otros en ausencia de amenazas o uso de sanciones negativas, poder es la habilidad de canalizar la conducta de otros por la amenaza o uso de sanciones negativas" (Fried, en Bechis 1989:2). 
Aunque la identificación de posicionamientos políticos distintos en la sociedad indígena no estuvo ausente (Bechis 1999), los mismos no fueron analizados específicamente en relación a las políticas desarrolladas por los estados. La pregunta por las transformaciones en las modalidades de acción política indígena quedó acotada por esta noción de segmentalidad, cuyas propiedades dinámicas y flexibles ofrecían un panorama en el que tanto la competencia como la alianza resultaban funcionales a la resistencia ante el blanco (Bechis 1989, 1999)7.

Algunos trabajos, sin embargo, comenzaron a poner el acento en los cambios operados en el ordenamiento político del mundo indígena y en especial en las características del cacicazgo, como consecuencia de las relaciones mantenidas con los asentamientos coloniales. N acuzzi $(1993-94,1998)$ atribuyó la transformación de los cacicazgos duales hacia cacicazgos unipersonales para el área de Pampa y N orpatagonia hacia fines del siglo XVIII a la influencia adquirida por ciertos jefes como interlocutores con los blancos. Las relaciones diplomáticas promovidas por la sociedad colonial con algunos caciques habrían repercutido, según esta autora, en la formación de "confederaciones indígenas", que sin embargo no habrían tenido mayor realidad o permanencia que la voluntad expresada en los tratados promovidos por la administración colonial (N acuzzi 2008).

Posteriormente, otras propuestas identificaron para la primera mitad del siglo XIX las condiciones para la transformación política hacia "grandes cacicatos" (Varela y Font 1996; M andrini 2002), "sociedades de jefatura" (Villar y Jiménez 2003) o "jefaturas de nuevo tipo" (Vezub 2005). Según estos autores, las posibilidades de enriquecimiento ligadas a la participación en los circuitos comerciales entre las Pampas y la Araucanía, las relaciones con los gobiernos coloniales así como los conflictos militares implicados por los procesos independentistas habrían permitido la jerarquización y diferenciación económica interna de los grupos indígenas, expresándose en un "sal to de calidad" (Vezub 2005:95) del poder de algunos caciques, que habrían incrementado su capacidad de coerción sobre sus seguidores. Bajo estas cabezas de gran prestigio se habrían configurado las grandes unidades políticas presentes en el espacio pampeano-norpatagónico a mediados del siglo XIX (Mandrini 2002).

7 En sus palabras, "la competencia por la sobrevivencia por medio de alianzas comerciales, políticas y militares con la sociedad criolla fue un ingrediente más en la estabilización de la segmentación política interna" (Bechis 1989). 
Ingrid deJ ong

Creemos sin embargo que profundizar en el análisis de la organización política en la sociedad indígena y en sus transformaciones hacia las últimas décadas de la frontera requiere revisar algunos aspectos de este panorama. En primer lugar, la transformación de la autoridad de los caciques hacia las "grandes jefaturas" conduce rápidamente a deducir la presencia de unidades étnico-políticas ocupando los ambientes ecológicos diferenciados al este de la cordillera - como la zona semi-árida del noroeste pampeano de los "ranqueles", los "pehuenches" en el norte de Neuquén y sur de Mendoza, los "salineros" en la zona oeste de la provincia de Buenos Aires, los "pampas" de la pampa húmeda al sudoeste de Buenos Aires, así como los "tehuelche-huilliches" de la zona interfluvial del Negro y el Colorado, en estrecho contacto con los "manzaneros" de la zona lacustre del N euquén-, reestableciendo así Ios límites propuestos por la clasificación de las fuentes del siglo XIX, en los que la asociación entre pertenencia étnica y conducta política tiende a naturalizarse. En este sentido, el uso equivalente de los términos unidad política/cacicazgo/parcialidad/jefatura/agrupación/tribu tanto para referirse a los seguidores de un cacique en particular como para aludir a los grupos mayores que en las fuentes son identificados como "ranqueles", "salineros" o "tehuelches", muestra que no sólo se nos escapan aún las prácticas concretas que fueron adoptando las conductas políticas indígenas sino que se corre el riesgo de imponer desde un inicio una representación "etnificada" de la legitimidad de los líderes y de los mecanismos de acción y decisión política en la sociedad indígena. Trabajos recientes como los de Delrio y Ramos (2006) muestran que el campo de la performance política indígena fue bastante más complejo. Analizando el "parlamento" como mecanismo de articulación política, los autores han destacado el funcionamiento de espacios sociales que impugnan "tanto los límites de las fronteras bi-nacionales como aquellos impuestos por gran parte de la explicación etnológica" (Delrio y Ramos 2006:5) ${ }^{8}$. Creemos, por tanto, que debe profundizarse el análisis del alcance de los lazos étnicos, de parentesco o de linaje así como las redes establecidas con diversos sectores de la sociedad no-indígena en la conformación de unidades políticas y en la misma praxis y representaciones indígenas.

8 Los parlamentos analizados por estos autores se presentan efectivamente como reuniones multiétnicas que vinculaban grupos de territorios distantes, configurando espacios donde se fortalecían circuitos de información y alianzas entre grupos y caciques según y en los que podían tomarse decisiones políticas con performatividad sobre las relaciones entre los grupos originarios y con la sociedad criolla (Delrio y Ramos 2006). 
En segundo lugar, y desde nuestra perspectiva, el énfasis en la progresión hacia las "grandes jefaturas" ha concentrado la atención en los indicadores relativos al poder de ciertos caciques ${ }^{9}$, relegando el análisis de las transformaciones del carácter segmental del conjunto de la sociedad indígena. Analizar las modalidades de acción política indígena en Pampa y norpatagonia durante el siglo XIX requiere poner en suspenso la idea de unidades políticas discretas y atender a los contextos, coyunturas y razones por las cuales potenciales vínculos de alianza podían activarse o distenderse. En este camino, la reconstrucción de la dinámica de las unidades políticas indígenas debería contar entre los factores explicativos tanto a los recursos organizativos propios de estos grupos, sus modalidades y márgenes de autonomía en la toma de decisiones políticas, como desplegar una mirada del proceso que, centrada en las políticas estatales y sus objetivos, identifique las transformaciones operadas por los dispositivos de estado sobre la conformación de alianzas políticas indígenas (de Jong 2007b).

Aunque las relaciones diplomáticas desarrolladas entre los grupos indígenas y el estado han sido contemplados entre los factores vinculados a la emergencia de jefaturas indígenas hacia mediados del siglo XIX, resta aún analizar su incidencia específica en la conformación de las unidades políticas y en los liderazgos de la segunda mitad del siglo. Esta influencia puede rastrearse ya en la diversificación de lugares y opciones políticas operada por el "negocio pacífico de indios" durante el gobierno de Rosas, política que fortaleció el papel de los "indios amigos" para aquellos caciques que a cambio de recibir raciones acordaran instalarse con sus seguidores en la línea de fronteras, subordinándose a las autoridades militares y realizando diversos tipos de tareas, que iban desde el empleo en estancias hasta cumplimiento de funciones de chasques y baqueanos (Ratto 2003). Este tipo de vínculo comenzó a diferenciarse así de los tratos con "indios aliados" (Bechis 1998) que aunque se comprometían a respetar las posesiones blancas de la frontera, mantenían su autonomía territorial. El "negocio pacífico de indios" habilitó a Rosas un control relativo de las alianzas indígenas, asegurando la fidelidad de algunos

9 De hecho, el grado en que los procesos derivados de la relación con las sociedades estatales trasformaron la organización política indígena se encuentra en discusión. Algunos trabajos apuntan a relativizar el cambio de la base voluntaria que unía a un cacique con sus segui dores, apuntando a que las negociaciones con el estado habrían consolidado el prestigio de al gunos caciques sin modificar el lugar del lenguaje de parentesco y la reciprocidad como mecanismo de legitimación política (Morrone 2004; Néspolo, Cutrera y Morrone 2007). 
Ingrid deJ ong

caciques bajo el objetivo de obstaculizar las incursiones fronterizas de otros. Pero será la política de "tratados de paz" desplegada por el estado nacional durante las presidencias de Mitre (1862-1868), Sarmiento (1868-1874) y Avellaneda (1874-1880) la que adquiera mayores alcances, impactando no necesariamente en el tipo de autoridad de los cacicatos sino en la dinámica misma de las alianzas indígenas. En este sentido, este impacto fue selectivo y supuso distintas transformaciones al interior del campo indígena.

La noción de "efecto sesgante de las relaciones secundarias"10, incorporada por Bechis para el análisis de las transformaciones de las sociedades indígenas en relación a la presencia estatal, se vuelve entonces imprescindible para analizar el comportamiento político indígena, camino en el que el punto de partida se confunde riesgosamente con el de llegada. Para esta autora, el sesgo de las relaciones estatales favoreció la influencia adquirida por algunos cacicazgos sin alterar el carácter segmental de la estructura política indígena. La influencia de los gobiernos durante el siglo XIX se habría orientado así a conservar la segmentalidad, aunque en unidades mayores - cuando estas eran parcialidades amigas- y a inducir la fisión de aquellas más problemáticas ante los intereses estatales, pero habría fracasado en sus intentos de cambiar la relación entre el cacique y los "mocetones" (Bechis 1999:7). Proponemos retomar aquí esta propuesta no desarrollada por la autora, considerando especialmente este elemento de heterogeneidad con el que permite observar la influencia estatal en la configuración de unidades políticas del campo indígena. Intentaremos desde este enfoque reconstruir la trayectoria política del cacique Calfucurá, haciendo hincapié en el marco de alianzas intra e interétnicas en los que fue tomando forma su liderazgo.

\section{Los vínculos con el Estado en la emergencia del liderazgo de Calfucurá}

El propio crecimiento del liderazgo de Calfucurá en las Pampas no puede entenderse sin atender a las relaciones de alianza que este cacique va tendiendo tanto hacia diversos sectores del gobierno nacio-

10 Propuesta inicialmente por Fried, ella supone "un cambio en la complejidad de las instituciones políticas en presencia de sociedades más desarrol ladas políticamente" (Fried 1975, en Bechis 1999). 
nal como hacia el interior del campo indígena. Según las memorias de Santiago Avendaño (1999), Calfucurá inicia sus incursiones en las Pampas en la década de 1830 como conductor de malones, cuyos éxitos reiterados fueron consolidando su prestigio. Sin embargo, su instalación definitiva en Salinas Grandes, espacio estratégico para el comercio de la sal y la circulación de ganados, fue posibilitada también por las relaciones diplomáticas que fueron desarrollándose entre este jefe y Juan M anuel de Rosas, quien encontró en las negociaciones con Calfucurá la manera de oponer un obstáculo a las incursiones fronterizas de otros grupos. Aunque este jefe había ingresado ya a principios de la década de 1840 al "negocio pacífico de indios", el control de abundantes recursos en sal para comerciar y una hábil diplomacia que combinaba la recepción de raciones con excursiones de saqueo de ganado sostuvo a Calfucurá en el comercio con distintos grupos chilenos al mismo tiempo que colaborando en el mantenimiento de una relativa paz en las fronteras (Ratto 2006). En estos años, Calfucurá fue construyendo una extensa red de relaciones con los líderes indígenas en distintos espacios: con Catriel y Cachul, los principales jefes que formaban parte del negocio pacífico en la zona de Azul y Tapalqué, con cacique ranquel Pichuin y los grupos "picunches" del norte del actual Neuquén (de Jong y Ratto 2008). Al mismo tiempo, mantuvo sus contactos con las agrupaciones del área cordillerana, donde su hermano Reuquecurá controlaba uno de los pasos estratégicos que comunicaban las Pampas con la Araucanía. A través de este cacique, los vínculos de solidaridad militar y económica de los "salineros" con grupos "arribanos" y "huilliches" del territorio trasandino parecen haberse articulado desde estas primeras etapas de instalación de Calfucurá en Salinas Grandes ${ }^{11}$. La expansión de sus alianzas parece haberse extendido asimismo a los caciques Chocorí y Cheuqueta, de

11 Los "arribanos" o "moluches" y los "huilliches" ocupaban en la segunda mitad del siglo XIX las faldas cordilleranas entre el río Malleco y el Toltén, manteniendo un contacto fluido con los grupos salineros, ranqueles y pehuenches a través de los boquetes de Villarrica, Ical ma y Antuco. El mismo Calfucurá era oriundo de esta región, habiendo nacido en Pitrufquén y formado su cacicato a los pies del volcán Llaima (Guevara 1913; Bechis 1999). Salvo el trabajo de Leonardo León Solís (1981), no se han real izado hasta el momento trabajos que reconstruyan en base a documentos la evolución de estas relaciones político-comerciales. Como veremos, los principales caciques que encontramos en las fuentes del período analizado son los arribanos de Quilapán, Quilahueque y Marihual, princi pales líderes de la resistencia indígena ante el estado chileno, quienes son anunciados por Calfucurá en sus cartas a los comandantes de frontera, e invitados a Salinas Grandes con el objetivo de invadir o comerciar en las fronteras bonaerenses. 
Ingrid deJ ong

la zona del Limay. Allí se había refugiado Calfucurá ante el ataque de las fuerzas militares enviadas por Rosas en 1838 y posiblemente antes, cuando la Campaña de 1833 buscó reprimir y desarticular aquellos grupos más activos en la actividad malonera sobre las fronteras. Según Villar y Jiménez (2003) la práctica simultaneidad de los pactos firmados por ambos caciques con Rosas a mediados de la década de 1840 indicaría la fuerte alianza que se habían establecido entre ambos grupos, sostenida también por lazos de parentesco.

Al amparo de sus acuerdos de paz con el gobierno de Rosas, Calfucurá parece haber dispuesto de un espacio de expansión de su prestigio, vinculado a la posibilidad que las raciones recibidas le daban - como "dador de obsequios"- de ampliar su protagonismo en las relaciones diplomáticas intertribales (Ratto 2003, 2006) ${ }^{12}$. Es posible, sin embargo, que los paliativos dados por las raciones obtenidas en los acuerdos en la frontera a las limitaciones que estos significaban para su expansión comercial fueran transformando las estrategias políticas de Calfucurá, acercándolo ya a fines de la década de 1840 a caudillos opositores al régimen rosista. En 1849 se registra el primer intento de coalición bajo su mando para realizar un ataque a la frontera bonaerense como respuesta al avance de las poblaciones criollas sobre "sus campos y estancias". Aunque esta convocatoria - que contaría con grupos llegados de Mendoza y Chile así como con el apoyo de indios de Tapalqué- no llegó a concretarse, representa el primer intento de movilización de las alianzas establecidas a lo largo de la última década (de Jong y Ratto 2008).

La caída de Rosas, el desarrollo de la división política y la confrontación militar entre federales y unitarios parecen haber conformado el contexto más favorable al fortalecimiento de su liderazgo y junto a él, de lo que se ha considerado la mayor experiencia de unidad del campo indígena (Bechis 1999). La nueva política de fronteras del estado bonaerense hace colapsar el "negocio pacífico de indios". Se suspenden los racionamientos y el avance militar sobre territorios indígenas provoca la resistencia de muchas tribus amigas instaladas en la frontera, a las que el gobierno enfrenta con el Ejército de 0 peraciones del Sud. Este panorama constituye un contexto significativo

12 Desde mediados de la década de 1840 y hasta la caí da de Rosas, la entrega de ganado y bienes de consumo al grupo liderado por Calfucurá fue constantey voluminosa Según Avendaño, la percepción mensual de 2000 cabezas de ganado equino y vacuno habría posi bilitado que el grupo gozara de cierta riqueza y que "no hubiera indio que no tuviera hacienda que cuidar" (Avendaño 1999:59, en Ratto 2003). 
para Calfucurá, que paralelamente a la negociación, por intermedio de los ranqueles, de un tratado con U rquiza - líder de la Confederación de Provincias en pugna con el Estado de Buenos Aires- en 1854, extiende su convocatoria a la coalición sobre distintas agrupaciones del área pampeano-norpatagónica, entre los que se incluían ranqueles, tehuelche-huilliches y pampas, integrando a las numerosas tribus de Catriel y Yanquetruz. En un contexto en el que el avance del ejército de Buenos Aires y la resistencia opuesta por Calfucurá no dejaba lugar para la neutralidad, esta Confederación parece haber obtenido el apoyo simultáneo de distintos sectores indígenas, incluso mediante intentos de sumar por secuestro a las tribus amigas remisas de la frontera bonaerense, como las de Cristo, Rondeau, Guayquil, Garay y Ancalao (Hux 1991).

Los numerosos malones de la Confederación Indígena, especialmente a lo largo del año 1855, parecen haber propagado el terror entre los pobladores de la frontera, y a ellos se ha atribuido un retroceso de la ocupación hacia límites previos a los del gobierno rosista. Bajo la aparente sujeción al liderazgo de Calfucurá, la participación de los distintos sectores indígenas en los episodios de estos años respondía también al surgimiento de frentes de conflicto en las distintas jurisdicciones de frontera, relacionados con el cambio del personal militar y el carácter ofensivo asumido por la política del Estado de Buenos Aires. Aunque encontramos a caciques como Yanquetruz y Sayhueque participando junto a lanceros de Calfucurá de algunos de estas incursiones, como el malón de San Antonio de Iraola (1855), observamos un paulatino retorno a situaciones de desavenencia intergrupal previas a la coalición, ligadas a dispares intereses en mantener relaciones pacíficas con la jurisdicción de Patagones (Vezub 2005). En este sentido, la Confederación Indígena no continuará unida mucho tiempo más: si bien algunos continuarán formando parte de la jefatura de Calfucurá, otros de sus integrantes buscarán retomar sus vínculos particulares con distintas jurisdicciones fronterizas, mientras que muchas de las tribus "secuestradas" retornarán a la frontera buscando recuperar su status de "indios amigos". A ello colaborará fundamentalmente el cambio de la política de fronteras del gobierno bonaerense, cuyo retorno a los métodos diplomáticos buscaría estabilizar la conflictividad que habían adquirido las relaciones con los indígenas en los años posteriores a la caída de Rosas. 
Ingrid deJ ong

\section{La política de tratados de paz en la segunda mitad del siglo XIX}

Reorientando las acciones de confrontación militar, a partir de 1856 se emprenden tratativas de paz desde los fuertes de Bahía Blanca y Carmen de Patagones, los principales puntos de la sección sur de la frontera, a las que responden varias tribus pampas y huilliches que se desgajan de la Confederación Indígena. Muchos de estos caciques se habían integrado como indios "amigos" o "aliados" en tiempos de Rosas, y aspiraban a regresar a este tipo de relaciones con los blancos.

D esde el Fuerte Argentino, en Bahía Blanca, se realiza en 1856 un tratado con Juan Catriel, quien retorna al sur de la frontera bonaerense bajo el título de "Cacique Mayor y Comandante General de las Pampas", con sueldo mensual, grado de general y uso de charreteras de coronel, encomendándole su mediación en la restitución de cautivos y en el ofrecimiento de condiciones de paz a Calfucurá. Catriel, cuyo padre ya había entrado en tratos pacíficos con el gobierno bonaerense en 1827, mira con preferencia la opción de volver a vivir en la frontera. Su retorno a las tierras cercanas a Azul es acompañado en los años inmediatos por numerosas tribus pampas que se ubican en las tierras cercanas de Tapalqué.

D esde Patagones se inician tratativas con Yanquetruz, con quien se firma un tratado en 1857 por el cual se lo considera el "Comandante en Jefe de todo el territorio de la Pampa que es adyacente a la jurisdicción de Patagones", incluyendo a los principales caciques del sur neuquino, comprometiéndolo a ceder trece leguas de territorio a la provincia de Buenos Aires, defender las costas marítimas del Atlántico ante una incursión extranjera y apoyar militarmente cualquier intento de exploración u ocupación nacional del curso del río Negro. Al morir Yanquetruz en 1858 se realiza un tratado en términos similares con su hermano Chingoleo. Este cumple en los primeros años de la década de 1860 un estratégico papel de intermediario diplomático, acercando a varios caciques que habitaban las márgenes del río $\mathrm{N}$ egro y las faldas cordilleranas para negociar tratados de paz. Aunque no todos se concretaron, constituyeron medidas disuasorias hacia caciques que participaban en las invasiones de Calfucurá (Levaggi 2000).

Los esfuerzos de Buenos Aires se dirigieron asimismo a captar el apoyo de caciques ranqueles más cercanos a las fronteras de San Luis y Córdoba, que se hallaban bajo tratados con U rquiza. En 1858 se entrega una copia del tratado realizado con Yanquetruz al unitario Baigorria, 
líder de los ranqueles, para invitarlo a entrar en tratos similares. Si bien no prosperan inmediatamente, estas tratativas tienen sus resultados a largo plazo. El boroga Coliqueo, quien aparece en varias fuentes como "cacique segundo" de la Confederación Indígena, independiza a mediados de 1861 su juego de alianzas con Calfucurá al seguir al coronel Baigorria en su ruptura con U rquiza y apoyar a Mitre en su enfrentamiento con la Confederación. A ello habría sucedido el incorporación de la tribu de Coliqueo como "indios amigos" en la zona de Bragado, en el sector oeste de la frontera bonaerense $(\mathrm{H} \text { ux } 1980)^{13}$. Este traspaso parece haber repercutido directamente en la conducta de Calfucurá, quien a través de la intermediación de Catriel con el Comandante de Azul, pide un tratado de paz que termina por concretarse a mediados de 1861, comprometiéndolo como "aliado" a alertar sobre invasiones.

La política de "tratos pacíficos" tomó mayor fuerza tras la derrota de la Confederación de Provincias y la unificación política bajo la presidencia del porteño Bartolomé Mitre (1862-1868). Sayhueque, cacique del sur cordillerano neuquino que figuraba en el tratado que Chingoleo firma luego de la muerte de Yanquetruz (1859), renueva sus vínculos con el gobierno bajo un tratado particular (1863) que revela su ascendencia como jefe de las tribus del Limay. A su vez, los tratados realizados desde Patagones con los tehuelches Francisco (1865), Andrés (1865) y Casimiro (1866) avanzaron en la integración a los tratos pacíficos sobre las poblaciones al sur del río N egro, orientando el apoyo indígena hacia el resguardo de la soberanía y colonización de los territorios patagónicos.

Las alianzas que estableció el emergente gobierno nacional fueron tomando así la forma de una red, en la que algunos caciques destacados por estas relaciones funcionaron como intermediarios para sumar a nuevos aliados, hasta cubrir gran parte del mapa político indígena. Como prácticas de la diplomacia blanca, constituyeron valiosos instrumentos para dar un orden adecuado a las negociaciones, conseguir diferentes tipos de apoyos por parte de distintos grupos y aislar políticamente a los sectores que, como los salineros de Calfucurá, o los ranqueles, oponían mayor resistencia a los avances fronterizos. Las relaciones diplomáticas con estos últimos, por otra parte, se habrían

13 Este cambio de bando parece haber tenido un efecto importante en la reorganización de las alianzas intra e interétnicas. En los siguientes años, y hasta 1865, cuando se formal iza un primer tratado entre ranqueles y el gobierno nacional, ranqueles y salineros mantendrán al ianzas dispares, con las montoneras provinciales los primeros y con el gobierno nacional en la frontera bonaerense los segundos (Tamagnini, Olmedo y Pérez Zavala 2002). 
Ingrid deJ ong

dirigido a controlar el apoyo proporcionado a las montoneras que se mantenían en pie contra el gobierno central. De hecho la realización de tratados de paz con los ranqueles $(1865,1870$ y 1872) participó de una progresiva ruptura del equilibrio de poder en las relaciones intra e interétnicas, proceso en el que el estado fue adquiriendo mayor poder para legitimar sus planes de avance y sus acciones punitivas contra los indígenas (Tamagnini y Pérez Zavala 2007).

Si el retorno a los tratados de paz había desgajado rápidamente a los pampas de Catriel y a los huilliches de Yanquetruz de la coalición que habían integrado en 1855 junto a Calfucurá, este proceso de desgranamiento continúa durante los años siguientes, una vez que éste también entra en tratados con el gobierno nacional ya unificado, involucrando a caciques que mantenían con él distintos vínculos de alianza o subordinación. Sin embargo, en sentido inverso a la concentración de la representatividad de caciques como Chingoleo o Sayhueque, fue frecuente que jefes cercanos a Calfucurá se independizaran de éste, acercándose a las fronteras para formalizar tratados particulares. Uno de ellos fue su hijo Millacurá, que desde 1858 aparece racionado junto a Catriel y Cachul. Le sigue su cuñado Ignacio, admitido a fines de 1862 como indio amigo en el Fuerte Argentino de Bahía Blanca. En los siguientes años se incorporan Manuel Grande (1864), Cañumil (1865), Guayquil (1866) y Q uentriel (1866), quien había sucedido a Coliqueo como cacique segundo de Calfucurá.

El lugar de Calfucurá como "redistribuidor de raciones" podría estar relacionado con este proceso de desgranamiento, en tanto este jefe parece haber sido objeto acusaciones por varios de sus caciques, que no creían recibir lo suficiente ${ }^{14}$. El cacique, en su faceta de "líder gestor de raciones en tiempos de paz", dejaba seguramente qué desear a sus funciones como "líder malonero en tiempos de guerra". Los "tiempos de paz" parecen haber limitado su autoridad como líder en gran escala, y hasta cierto punto, parece haberla condicionado en

14 Es claro, por ejemplo, que ed reparto de las raciones no parecía cumplir con las expectativas de caciques como Cañumil, que bajo el argumento de que Calfucurá "no les pasaba nada de lo que recibía por el Azul" se acercó acompañado de capitanejo Guayquil en septiembre de 1863 a la Comandancia de Bahía Blanca, manifestando "el deseo de desligarse de Calfucurá y establecerse con su gente en las inmediaciones de este pueblo, bajo la dependencia del Superior Gobierno". J osé O. Llano al Ministro de Guerra Gral. Juan Gelly y Obes, 18/4/1864, Servicio Histórico del Ejército (SHE), Caja 13, Doc. №8841. Calfucuráa su vez sequejaba por aquellos años que luego de repartir las raciones no había quedado nada para su tienda (Hux 1991:76). 
relación a sus caciques aliados más inmediatos ${ }^{15}$. Pero este desgranamiento constituyó, por otra parte, un efecto especialmente buscado por la política de fronteras del período, que amplió su oferta de tratados favoreciendo la instalación de nuevos "indios amigos" en las distintas jurisdicciones de frontera. Al mismo tiempo, la opción por negociar tratados particulares tomada por muchos caciques constituía una conducta lógica dentro de las pautas segmentales de la organización política indígena y nos habla de un amplio abanico de posicionamientos entre los mismos, incluyendo aquellos que buscaban negociar las condiciones de una inserción estable en la sociedad estatal. "Fundar un pueblo y vivir en la frontera" formaba parte de las expectativas de caciques como Q uentriel y Manuel Grande al iniciar sus negociaciones particulares en la comandancia de Azul. Ello nos indica, a su vez, que ingresar a la condición de "indio amigo" no fue necesariamente percibido por estos caciques como un proceso de sometimiento sino como un proyecto compatible con el mantenimiento de cierta cuota de autonomía política (de Jong 2007a).

En resumen, los tratados de paz colaboraron a reorganizar el mapa político indígena, ejerciendo efectos diferentes en los distintos grupos que, en función de estas negociaciones, fueron perfilándose como sectores de población con una más clara demarcación territorial y con representantes políticos más jerarquizados y estables. Para algunos de ellos los tratados aseguraron una modalidad pacífica de obtención de ganado - en base a la percepción de raciones periódicas y al intercambio comercial en los puntos de frontera- que no siempre entró en contradicción con los planes estatales de exploración y ocupación del territorio pampeano y patagónico. Si este parece haber sido el caso de muchos de los caciques "huilliches", "manzaneros", "tehuelches" y "pehuenches" que mantuvieron tratados por Patagones, distinta fue la dinámica de relación con "salineros" y "ranqueles", participantes activos en el circuito comercial con Chile y ubicados en los territorios más próximos a la frontera.

15 Al respecto, debetenerseen cuenta quelas raciones acordadas en el tratado con Cal fucurá eran notablementemenores a las percibidas durante el período rosista. Aunque no se ha encontrado en los archivos ejemplares del tratado firmado por Calfucurá con el Gobierno de Buenos Aires en 1861, según la referencia del Teniente Coronel a cargo de las comisiones de indios, J uan Cornel, este cacique recibía trimestralmente-y ya no mensual mente- "dos mil yeguas y los artícul os de ración pa. distribuirlos a sus tribus". Juan Cornell al Ministro de Guerra y Marina Juan Nelly y Obes, 10/11/1863. SHE, Caja 12, Doc. № 699. 
Ingrid deJ ong

\section{Calfucurá y el "troquelado" del mapa político indígena}

En efecto, el despliegue de la política de tratados de paz desde fines de la década de 1850 en adelante tenderá a dejar a salineros y ranqueles como los grupos principales en resistir los intermitentes intentos estatales de avanzar las fronteras. Cada uno de los intentos de exploración u ocupación de los territorios indígenas - lejos de integrar los compromisos asumidos en los acuerdos de paz con los salineros-, provocó reacción de Calfucurá, cuyas amenazas invasión, sin embargo, no siempre llegaron a concretarse.

La difusión de un proyecto de avance las fronteras planificado por el Ministerio de Guerra y la fundación del fortín 9 de Julio en el oeste bonaerense en 1864 es seguida por invasiones a la frontera de Córdoba y Santa Fe por tribus ranqueles y salineras. Aunque Calfucurá amenaza con un gran malón combinado entre ranqueles, salineros y "chilenos"16 éste finalmente no se concretó, quizás como resultado del intento del gobierno de recomponer las relaciones pacíficas mediante regalos y el ofrecimiento de un tratado de paz a los ranqueles. Poco después, cuando a mediados de 1865 se dispuso el avance de la frontera bonaerense a partir de la creación de diez nuevos partidos, Calfucurá protesta por vías diplomáticas, pero, paralelamente, convoca al cacique Trecán de Valdivia, quien cruza la cordillera junto a 2000 indios "chilenos" (H ux 1991). Este grupo acompañó a fuerzas salineras que, a parecer en combinación con ranqueles y la anuencia de los indios de Catriel, real izaron invasiones a la frontera sur y oeste de Buenos Aires a fines de ese año ${ }^{17}$. Estas primeras situaciones de confrontación posteriores a la realización de tratados de paz con estado nacional unificado muestran que la invasión en gran escala -como acción o como amenaza- seguía formando parte de la estrategia Calfucurá. Pero en esta coalición - donde se reactivaron alianzas entre salineros, ranqueles e indios provenientes del oeste cordillerano- ya no se contaban todos los grupos que habían estado presentes en 1855.

16 Según lo informaba el gobernador de la Araucanía, los caciques que habían atravesado la cordillera para reunirse con Calfucurá eran Neuquepán, de Boroa; Marivil, de Maquehua; Quilapán, de Collicó y Payllagüeque de Perquenco, quienes finalmente sólo realizan invasiones menores a la frontera (Hux 1991:78). Pese a la presencia de estos caciques, parece claro que Calfucurá mantenía la capacidad de orientar el curso de las relaciones fronterizas hacia la confrontación o hacia la continuidad de las negociaciones.

17 Carta del coronel Benito Machado al Ministro de GuerraJ ulián Martínez. SHE, Caja 19, Doc. № 854 . 
Un nuevo movimiento conjunto se produce a comienzos del año 1866, cuando el comandante de la Frontera Sur, Benito Machado, acusando a Calfucurá de participar en las últimas invasiones, suspende la entrega de raciones y detiene a la comisión que había concurrido a recibirlas ${ }^{18}$. Calfucurá comunicó que mandaría llamar en su apoyo a indios "chilenos" y de la cordillera, y que contaría también con las fuerzas de ranqueles e indios de Catriel (Barros 1975 [1872]). E inmediatamente envió un malón sobre Tres Arroyos, donde se había adelantado la frontera en cuarenta leguas (Hux 1991). Hacia mediados del año, los partes militares de Álvaro Barros - sucesor de Machado en la Comandancia de Azul- transmiten que Calfucurá anunciaba la llegada a Salinas Grandes de 3000 guerreros (en documentos posteriores habla de 1500) de su hermano Reuquecurá desde la Cordillera, acompañado por los caciques Paillacán y Cayupán, con "quinientos chilenos"19. Pero esta amenaza de invasión conjunta logró ser reorientada por el comandante Barros, el gobierno nacional y los mismos caciques hacia la gestión y renovación de tratados de paz. En octubre de 1866 se firmaba un nuevo tratado de paz con Calfucurá y un primer tratado con Reuquecurá, una vez más, en los toldos de Catriel, quien parece haberse conducido como articulador diplomático de este proceso. Durante el desarrollo de estas negociaciones arriba al Azul una comisión de 400 indios liderada por Sayhueque (quien ya mantenía un tratado por Patagones) con el objetivo de enviar una comisión a la Capital para la firma de un nuevo tratado en el que se le acordaran raciones trimestrales como a los caciques Reuquecurá y Calfucurá.

En contraste con esta presencia competitiva de Sayhueque, los principales aliados de Calfucurá parecían ser los indios cordilleranos movilizados por Reuquecurá, además del apoyo "diplomático" del

18 Los intereses creados en base a la administración de las raciones para el ejército, guardias nacionales e indios amigos en las jurisdicciones fronterizas -que daban lugar a importantes ganancias-formaban parte de estos conflictos. El propio coronel Machado fue acusado a raíz de este incidente por manejos fraudulentos de las raciones asignadas al cacique y destituido temporal mente de su cargo. Según el coronel Alvaro Barros-en aquellas circunstancias subordinado de coronel Machado como J efe 20 de la frontera Costa Sud-, éste había recibido aviso de Calfucurá sobre las invasiones que preparaban chilenos y ranqueles, pero había silenciado la información y manteni do inmóviles las tropas con la mira de forzar a Cal fucurá a la real ización de nuevos tratados bajo su supervisión. En el contexto de la Guerra del Paraguay y la falta de personal militar para repeler un ataque de fuerzas indígenas combinadas, ésta no parecía ser la decisión más acertada (Barros 1975 [1872]).

19 Carta deÁlvaro Barros al Ministro de Guerra J ul ián Mart́nez, 22/8/1866. SHE, Caja 20, Doc. № 3588 y № 893. 
Ingrid deJ ong

cacique amigo Juan Catriel. Sin embargo, este no era un rasgo general entre los indios amigos: Calfucurá intentará en estos años reestablecer sus contactos con Coliqueo, a quien invita a parlamentar enviándole una carta en la que lo reconoce como "Señor General y Cacique Principal de las tribus amigas de la República Argentina", un esfuerzo diplomático que no parece haber sido retribuido por el cacique borogano (Hux 1991:83).

Aunque con intermitencias, algunas fuentes permiten inferir que la alianza con los caciques ranqueles y salineros continuó activándose bajo el pedido de uno u otro grupo. Es así que hallamos a Calfucurá participando a principios de 1867 en un ataque en la frontera de Córdoba (Schoo Lastra 1928, en Bechis 1999). Pese a la sanción de la Ley 215 de 1867 - que establecía el adelantamiento de la línea de fronteras hasta la margen septentrional de los ríos $\mathrm{N}$ euquén y $\mathrm{N}$ egro-, seguida por la definición de un plan para su concreción una vez terminada la Guerra del Paraguay por parte del Ministro Gainza y el inicio de importantes desórdenes en la entrega de raciones, Calfucurá prefiere no confrontar con el gobierno durante gran parte del año 1868. Sin embargo, cuando el presidente Mitre ordena ocupar la isla de Choele Choel, punto central en el recorrido de los ganados comercializados hacia Chile, la reacción de los salineros fue inmediata: Barros (1975 [1872]) transcribe algunas de las cartas enviadas por Calfucurá y su sobrino Bernardo N amuncurá, anunciando que se había mandado llamar nuevamente a las fuerzas de Reuquecurá, para que lo apoyara en caso de que quisieran ocupar la isla y hacerle la guerra. U nos meses después, reitera esta amenaza, anunciando el inminente arribo de su hermano con 3500 lanzas. El cacique también anuncia los éxitos militares de Quilapán, Calfú Coi, Marihual y Calfuén en la frontera chilena, y los planes de Q uilapán de cruzar la cordillera con 3000 de sus guerreros. Pero estas no pasaron de ser amenazas de invasión, en parte porque el recién electo presidente Sarmiento decide retirar las tropas de la isla20.

Creemos, llegado este punto, que puede señalarse una tendencia que marca la dinámica de las alianzas militares de Calfucurá en esta

20 Sabemos también que los caciques que Cal fucurá presenta como al iados militares se hallaban en el momento más ál gido de su levantamiento contra el ejército chileno, queen 1869 traslada la lucha al corazón del territorio de los "arribanos". Sin embargo, la derrota indígena implicará posteriormente una importante migración de grupos indígenas a las pampas durante el año 1870, los que partici parán probablemente en las confrontaciones lideradas por Cal fucurá (León Solís 1981). 
década: éstas parecen haberse mantenido con los grupos del este y el oeste de la Cordillera de los Andes, mientras que tendieron a volverse más inestables entre aquellos grupos del ámbito pampeano que buscaron negociar sus propios tratados de paz con el estado (de Jong y Ratto 2008). Como vimos, el cacique Calfucurá mantendrá una fluctuante relación de establecimiento de tratados y amenazas de invasión que contarán con un apoyo intermitente de grupos ranqueles, cordilleranos y "chilenos".

Pero es sobre estas alianzas que la política estatal intentará intervenir utilizando como instrumento los tratados de paz. En 1865, el tratado de paz con los ranqueles Mariano Rosas y Baigorrita establecía en una de sus cláusulas el compromiso de tratar a Calfucurá y sus indiadas como enemigos. Si bien tiene vigencia sólo durante unos meses, éste continuará siendo uno de los objetivos centrales en el siguiente tratado, negociado en 1870 por Mansilla (Pérez Zavala 2007). En 1869 se firma un tratado de paz, que ya se venía gestando desde 1868, con el cacique chileno Lemunao (1869), sobrino de Calfucurá, al que se le adjudica terrenos en "El Chichinal" - a veinte leguas de la Isla Choele Choel-, encargándole - bajo la promesa de raciones y la futura construcción de un pueblo- , la vigilancia del paso y el aviso de cualquier intento de invasión. Se lo condicionaba asimismo a no reconocer ningún dominio ni autoridad en los caciques Calfucurá y Reuquecurá, ni en ningún otro cacique natural del país, 0 de Chile, considerándolos en adelante "súbditos argentinos" (Levaggi 2000:427-433). Si bien no debe deducirse un éxito inmediato en estas pretensiones de ordenar el campo de las alianzas indígenas, está claro que es el instrumento privilegiado por el estado desde las distintas jurisdicciones de frontera. Desde Carmen de Patagones se prosigue la captación de nuevos caciques para la firma de tratados: ya en 1868 figuran en las listas de racionamientos los caciques del centro-norte neuquino Q ueupumé, Purrán y Huincaleu y en 1872 son firmados en esta jurisdicción tratados con Q ueupumil y su hermano Yancamil, los que continuarán bajo el sistema de raciones hasta avanzada la década de 1870 (Raone 1985). También en 1872 es renovado el tratado mantenido con Sayhueque, al que se suma la firma de un primer tratado con el cacique Juan Ñ ancucheo, por los que ambos caciques aceptan permanecer bajo la autoridad de M anuel Linares, sucesor de Chingoleo como principal cacique amigo de Patagones. Desde San Rafael, las negociaciones iniciadas años antes se concretan asimismo en 1872 
Ingrid deJ ong

con la firma de un tratado con numerosos caciques del sur mendocino y norte neuquino (Levaggi 2000).

El desarrollo de estas prácticas diplomáticas permite entender la coyuntura creada en el campo intra e interétnico en los inicios de la década de 1870, que dará los primeros indicios de la fragmentación de la capacidad de resistencia indígena ante los proyectos de avance estatal. Forma parte importante de este contexto el fin de la Guerra del Paraguay, experiencia bélica que creó las condiciones políticas, legales y económicas para la conformación de un ejército nacional regular del que el estado no había podido disponer previamente en el avance de las fronteras interiores.

En septiembre de 1869 el Ministro de Guerra envía nuevamente una expedición destinada a ocupar la isla de Choele Choel, plan que como vimos, contaba con el apoyo del cacique Lemunao, instalado en las cercanías de la isla. Paralelamente, la comisión que Calfucurá había mandado para recibir raciones en Azul, es retenida por su comandante, Álvaro Barros. Calfucurá accionó en forma diplomática, solicitando el regreso de su comisión y anunciando que se le habían agregado dos nuevos caciques "chilenos", Güenchu Nahuel y Pichinlaf. También parece haber intentado contactarse con Coliqueo, nuevamente sin éxito (Hux 1991). Pero el inicio de las tareas de adelantamiento general de la línea de fronteras de Buenos Aires llevado a cabo por el Ingeniero Czetz, que implicaba privar a los indios de las principales aguadas que servían de puntos de apoyo en sus invasiones ${ }^{21}$, es respondido con malones de salineros y ranqueles en las nuevas zonas ocupadas. En esta frágil situación, y quizás por no contar con el apoyo de indios cordilleranos y "chilenos" aliados que había anunciado en los primeros meses del año, Calfucurá intenta proseguir la comunicación con las comandancias, alertando sobre una próxima invasión a Tres Arroyos por parte de los indios "chilenos" que habían cruzado la cordillera "para ocupar Choele Choel" (Romeo, en Hux 1991:87).

Pero los primeros meses del año 1870 traerán nuevas fuentes de conflicto, vinculados a la nueva política desplegada por los jefes de frontera que retomaron sus puestos al volver del frente paraguayo. Estos inician la represión sobre los indios amigos más vinculados a Calfucurá, agravando las relaciones con este cacique. En marzo de 1870 el comandante de la frontera de Bahía Blanca, José O. Llano,

21 Informe del coronel del ngenieros J uan F. Czetz al Ministro deGuerra Mart́n deGainza. SHE, Caja 31, Doc. № 18a 5620 . 
avanza sobre los campos de Cañumil, acusándolo de robo de ganado. Más de setenta lanceros son muertos, la tribu y el cacique apresado y su ganado saqueado. Ello provoca la reacción de Calfucurá, quien reclama su liberación amenazando con invadir el sur de la provincia. M usters, viajero que se hallaba en estos tiempos en los territorios patagónicos, comenta que Calfucurá había buscado para esta invasión el apoyo del principal cacique tehuelche Casimiro, a quien le envió el siguiente mensaje transmitido en parlamento: "Tengo el caballo pronto, el pie en el estribo y la lanza en la mano y voy a hacer la guerra a los cristianos, que me tienen cansado con su falsía" (M usters 1997 [1871]:230). También fue invitado el cacique Sayhueque. $\mathrm{N}$ inguno de los dos pedidos fue respondido afirmativamente, pues se consideró que este apoyo interrumpiría las buenas relaciones que se mantenían con Patagones.

Según Musters, un conjunto heterogéneo de grupos que reunían comitivas de "tehuelches", "manzaneros" y "araucanos" se reunió para tratar este pedido: tuvo lugar un parlamento que duró hasta la noche y fueron sancionadas las siguientes conclusiones: que Casimiro sería reconocido como comandante general del sur, extendiéndose su jurisdicción sobre todos los indios del sur del Limay; que con su ejército garantizaría la salvación de Patagones y pondría en jaque a los indios pampas de Salinas, mandados por Calfucurá, en el improbable caso de que quisiera atravesar el río Negro con el propósito de asaltar los establecimientos. Q ue todos unidos marcharíamos a las M anzanas a proponer a Shayhueque que garantice con su ejército la seguridad de la costa norte del río N egro, rechazando, si fuera necesario, a Calfucurá y defendiendo a Patagones (M usters 1997:233, destacado nuestro).

Un segundo parlamento tuvo lugar, efectivamente, más al norte, en los toldos de Sayhueque, al que habría asistido Linares, el principal representante de los indios amigos de Patagones, donde se reafirma la decisión tomada en el primero: Linares y Casimiro demostraron que era más conveniente rechazar la invasión, pues de otro modo perderían inevitablemente las provisiones de caballos y de ganado que les daba el Gobierno de Buenos Aires; y que era más provechoso recibir anualmente las raciones que asaltar y destruir los establecimientos del río N egro. Se resolvió unánimemente escribir a Calfucurá intimándole que no pasara de Bahía Blanca en sus hostilidades, y que Sayhueque estaba pronto a marchar en defensa de la costa norte del río N egro y defender 
Ingrid deJ ong

a Patagones de ese lado, a la vez que Casimiro defendería el sur, según arreglos aceptados (M usters 1997:265, destacado nuestro).

La amenaza de Calfucurá se traduce finalmente en un ataque a Tres Arroyos y un gran malón en Bahía Blanca, este último dirigido por su hijo Namuncurá al mando de una fuerza de 2000 lanceros y otros caciques, entre los que estaban "algunos ranqueles" (Rojas Lagarde, en Hux 1991:89). No contamos con datos que nos permitan saber cuál fue la participación de los grupos ranqueles, que en ese año se hallaban gestionando un tratado con el coronel Mansilla, ni tampoco de los "chilenos"22, pero el jefe salinero no habría contado con el apoyo de caciques tehuelches y manzaneros, como tampoco de las indiadas de Cipriano Catriel - quien para entonces había sucedido a su padre Juan Catriel- en esta movilización.

Este último no es un dato menor: Cipriano parece haberse prestado más fácilmente que su padre a las manipulaciones políticas de los comandantes de frontera, quienes impulsarán una estrategia de división y confrontación entre los propios caciques amigos. Argumentando los frecuentes robos realizados por las tribus amigas, a fines de 1870 el comandante de Azul, Francisco de Elía, impulsa la firma de un convenio por el cual se otorgaba a Catriel el título de "jefe principal" de las tribus de la frontera sur. Ello implicaba la extensión de su autoridad a las tribus vecinas de Tapalqué, a las que se acusaba de robo de ganado y que a partir de ese momento fueron señaladas como "rebeldes"23. Este acuerdo llevo a Catriel a subordinar con el apoyo del ejército a las tribus de Manuel G rande, Chipitruz, Ramón López y Cachul, quitándoles sus ganados y encarcelando a los caciques y sus familias. Catriel iniciará con estas acciones un proceso de fragmentación en las alianzas con Calfucurá de difícil vuel ta atrás.

A comienzos de 1871 Calfucurá había retomado el diálogo diplomático en búsqueda de reestablecer los tratados de paz y entablar relaciones comerciales con los caciques "amigos" de la frontera oeste, Coliqueo y Raninqueo, con el argumento de que quería seguir en "buena armonía" y "estar de amigo con mi Gobierno que me sirve en

22 La fragmentación de alianzas indígenas se producía también tras los andes: a comienzos del año 1870, los grupos "arribanos" que resistían la ocupación de sus tierras, comandados por Quilapán, habían perdido no sól o el apoyo de los grupos "abajinos" del oeste, que habían parlamentado con el gobierno, si no también de varios caciques de importancia de los territorios cercanos al río Toltén (León Solís 1981).

23 Archivo General dela Nación (AGN), Memoria del Ministerio de Guerra 1871:246-248. 
muchas cosas para sostener mi indiada"24. Desde la comandancia de Bahía Blanca se había alentado a su vez esta propuesta de renovación del tratado de paz con Calfucurá, en función de cambiar prisioneros y ganar tiempo hasta reunir recursos e información para avanzar sobre sus tolderías ${ }^{25}$. Pero el ataque del ejército a los caciques amigos de Tapalqué rompe este proceso. Nuevamente circulan los rumores acerca de que Calfucurá está reuniendo 2000 hombres, entre ellos a grupos provenientes de Chile, para enfrentar lo que considera una afrenta al conjunto de la población indígena. O cho invasiones se producen a fines de 1871 en las cercanías de Bahía Blanca ${ }^{26}$.

Cuando en marzo de 1872 el ejército vuelve a ocupar Choele Choel, Calfucurá reacciona concitando un apoyo mayor que en ocasiones precedentes: sus indios invadieron el 5 de marzo diversos puntos del oeste bonaerense, intentando sumar a las tribus de los caciques amigos. La alianza entre salineros, cordilleranos de Reuquecurá, "chilenos" y ranqueles continuaba siendo el eje básico de la convocatoria. Entre los grupos que invadían se encontraban sus hijos Catricurá, con 1000 indios salineros, Manuel Namuncurá con 1000 indios "chilenos" y de río Negro, su hermano Reuquecurá con 1000 indios cordilleranos y "chilenos" y Epugner con 500 ranqueles $^{27}$. Esta fuerza de cerca de 3500 lanceros enfrentó a las tropas nacionales, que aunque inferiores en número, contaron con 250 indios de Coliqueo y 800 indios de Catriel, además de lanceros de Chipitruz y Manuel Grande (Hux 1991). Entre los aliados que Calfucurá tuvo en San Carlos, su última batalla, nuevamente estuvieron ausentes los manzaneros de Sayhueque, quien se hallaba por entonces en tratativas para renovar los tratados con Patagones. Considerado el inicio de la decadencia del poderío de Calfucurá, este enfrentamiento muestra además otro aspecto de la fragmentación de las alianzas indígenas provocados por el sistema de tratados desplegado en la segunda mitad del siglo XIX: las fuerzas del ejército nacional, notablemente inferiores en número, lograron imponerse gracias al apoyo decisivo de las tropas de Catriel y Coliqueo, tribus que mantuvieron su apoyo al ejército nacional,

24 Calfucurá al Coronel Boerr, Salinas Grandes, 21/12/1870. SHE, Doc. №6256.

25 Murga al inspector y comandante general de armas, Emilio Mitre. Bahía Blanca, 12/11/1870. SHE, Caja 32, Doc. № 1130.

26 AGN, Memoria del Ministerio de Guerra, Anexo C: 9.

27 Parte del Coronel Boerr, Archivo del Estado Mayor del Ejército (AEM) no 6482 y 6481, en Hux (1980:141). 
Ingrid deJ ong

aún cuando a partir del giro ofensivo de la administración fronteriza, habían comenzado a sentir no sólo la falta de raciones y el aumento de cargas militares, sino que eran objeto de represiones bajo la sospecha de "rebelión". De esta manera, las tribus amigas que habían cumplido hasta el momento un papel meramente disuasor o que, como las de Catriel, habían llegado incluso a participar en las movilizaciones de Calfucurá, se encontraban ahora actuando bajo la subordinación efectiva del ejército nacional ${ }^{28}$.

Calfucurá moriría un año después, en 1873, en el proceso de convocar un parlamento general que le permitiera consensuar los términos para negociar un nuevo tratado conjunto con el gobierno nacional. Suspendemos aquí este intento de reconstrucción, que deja por delante posteriores realineamientos de fuerzas indígenas a fines de la década de 1870 y comienzos de 1880, cuando el avance definitivo de los estados a ambos lados de la cordillera quiebra los procesos de negociación aún vigentes para el período que analizamos.

\section{A modo de síntesis}

El establecimiento de vínculos "pacíficos" - que implicaban la posibilidad de comerciar y recibir raciones a través de tratados de paz- fue una opción privilegiada por el amplio espectro de los agrupamientos indígenas de Pampa y Patagonia durante la segunda mitad del siglo XIX, y en tal medida respondía a modalidades de relación con el "blanco" propia de la lógica segmental del comportamiento político en la sociedad indígena. Sin embargo, creemos que la sistematicidad y extensión de su aplicación en las relaciones interétnicas permiten considerar a la política de tratados de paz como un dispositivo de poder estatal con importantes efectos en el ordenamiento de las alianzas al interior de la sociedad indígena. Impuestos bajo su forma escrita y una formulación jurídica por el poder estatal, devienen en el dispositivo hegemónico en los vínculos entre indios y blancos de la segunda mitad del siglo XIX. Si bien sus efectos inmediatos fueron visibles en la dispersión de la Confederación Indígena, repercutirán a largo plazo en la fragmentación de las alianzas que ésta había movilizado en la

28 En algunos casos esto no ocurrió sin resistencias: ante la renuencia de sus lanceros, Catriel solicitó al comandante Rivas que un piquete del ejército se ubicara tras sus fuerzas para matar a quienes no participaran de la batalla. AGN, X, 43-7-3, en Hux (1991:95). 
década de 1850. El despliegue de tratados de paz parece así haber "troquelado" el mapa de alianzas indígenas preexistente, tendiendo no solo a aislar diferentes unidades políticas sino a limitar y condicionar la autoridad de aquellas que se oponen a la expansión estatal.

En este sentido, los efectos en el campo indígena de la política de tratados de la segunda mitad del siglo XIX parecen haber sido dispares. $M$ ientras algunos caciques como Sayhueque, Casimiro o Chingoleo vieron incrementar su ascendencia y representatividad en función de sus negociaciones con el gobierno, el liderazgo de Calfucurá como jefe de la "Confederación Indígena" comenzó a verse afectado desde 1856, cuando los nuevos tratados ofrecidos por el estado de Buenos Aires desligan de su alianza a caciques pampas y huilliches. Con posterioridad observamos la continuidad de este desgranamiento entre aquellos caciques a que se hallaban bajo su influencia política inmediata. De esta manera, si bien la condición de "proveedor y redistribuidor de raciones" había permitido a Calfucurá incrementar su ascendencia sobre las tribus de pampa y norpatagonia hacia fines de la década de 1840, es probable que la extensión de la oferta de tratados a sus aliados y seguidores pueda haber limitado durante las últimas décadas de la frontera, esta concentración de poder (de Jong y Ratto 2008).

Multiplicando las cabezas negociadoras de intereses grupales, los tratados fueron logrando así diferenciar los intereses de sectores indígenas que privilegiaron su vínculo con el gobierno ante posteriores oportunidades de confederarse bajo el liderazgo de Calfucurá. Las convocatorias a la confrontación militar organizadas por este cacique durante la década de 1860 no contaron ya con la participación de los grupos del Limay, representados por Sayhueque, ni por la mayor parte de los indios amigos reinstalados en la frontera bonaerense. Merece señalarse, sin embargo, el papel que caciques como Catriel podían jugar en la trama de las relaciones interétnicas, manipulando con estrategia su capacidad de convertirse en articulador diplomático o derivar en aliado militar de uno u otro bando, nutriendo así un particular y ambiguo espacio de poder en las fronteras. Pero este espacio de poder, así como la potencialidad de alianza que contenía, se verá transformado en la década siguiente. Es una vez finalizada la Guerra del Paraguay que queda en evidencia el cambio en la correlación de fuerzas resultado de las negociaciones entre el estado unificado y los distintos sectores del conjunto indígena. 
Ingrid deJ ong

Creemos indispensable considerar la heterogeneidad de posicionamientos de este conjunto para comprender tanto los efectos de los dispositivos estatales como la dimensión de la propia agencia política indígena, con sus contradicciones y complejidades. Estas llevan a preguntarse por las representaciones que viabilizaban distintos proyectos indígenas de incorporación a un estado que daba muestras de su capacidad de expansión y consolidación, así como por las condiciones materiales y organizativas de los distintos grupos que fueron canalizando relaciones cualitativamente diferentes con los poderes estatales. Estas trayectorias constituyen el resultado complejo de un conjunto de factores entre los que deben contarse diferentes historias territoriales, la competencia por el dominio de pasos cordilleranos, así como tramas de parentesco y conflictos de distinto espesor. Sin embargo, si bien estos elementos habían permitido durante gran parte de la historia indígena una dinámica fluctuante de alianzas, creemos que los tratados de paz influyen en la "contracción del tejido social" (Boccara 2003) y fragmentación política de los sectores indígenas que van perfilándose en función de sus diferentes relaciones con el estado.

Se abre así un espacio para comprender el primer elemento de cambio distinguido por Bechis (1999) como "efecto sesgante" de las políticas estatales, el de la transformación en el tamaño de las unidades políticas indígenas en pos de limitar o desarticular la resistencia a la ofensiva territorial y, creemos, en la cristalización de sus diferencias políticas internas y sus divergentes posicionamientos ante el estado. En este sentido, entendemos el alcance del efecto sesgante de las situaciones secundarias no sólo o necesariamente debe buscarse en relación a la concentración del poder en la figura de los caciques, sino en la misma configuración de las alianzas entre las unidades políticas indígenas. Sostenemos que si bien la estructura segmental poseía un carácter flexible que admitía procesos de fisión y recomposición de la alianza, a lo largo de la segunda mitad del siglo XIX el estado va adquiriendo el poder de intervenir y cristalizar dicha flexibilidad. Ello no supone dejar de lado el peso de trayectorias de linaje y de ocupación territorial, así como decisiones e iniciativas políticas "gestadas en el interior de los toldos" (Vezub 2005) que continuaron influyendo en la oposición y distancia política entre parcialidades, a los que debería incorporarse el alcance de lo que consideramos una nueva y creciente influencia de las relaciones establecidas con el estado sobre las fricciones y enemistades entre las distintas etnias. En este sentido, 
lo que se nos presenta como posicionamientos políticos de grupos étnicos diferentes debe considerarse como el resultado combinado de trayectorias indígenas y de intentos estatales por segmentar un continuum que contenía potencialidades plásticas para la alianza. Y en esta misma dirección, el sesgo estatal no habría conservado necesariamente la segmentalidad - entendida como el carácter de lazos entre unidades equivalentes que conservan la potencialidad de fisionarse o fusionarse en forma fluctuante- sino favorecido una fragmentación que limitaría paulatinamente la fluctuación con la que estos segmentos participaban en una organización política laxa. En tanto dispositivos de poder que apuntaban a negociar con los caciques principales, los tratados de paz propiciaron una cristalización de la autonomía de los distintos segmentos o agrupaciones políticas para hacer prevalecer, en la conducta de los caciques, sus negociaciones particulares con el gobierno más que con otros segmentos indígenas. Esta articulación entre estado-cacique-seguidores a través de tratados de paz y acuerdos de racionamiento rompería con la imagen de una segmentalidad política indígena funcional a la defensa de su autonomía territorial.

Esta aproximación deja por delante el seguimiento de temas aquí solo recién iniciados. Entre ellos, el de la alianza con los grupos de la cordillera y "chilenos", que parece presentar la continuidad y solidez de las que carecen las relaciones entre los grupos del espacio pampeano-patagónico. Enfocar este tema, clave para el análisis de las alianzas indígenas en este período, requiere todavía descorrer el velo de homogeneidad que nos presentan las fuentes bajo el rótulo de "chilenos", para identificar los grupos y líderes involucrados en las alianzas militares y económicas con los grupos instalados en el oriente cordillerano, y analizar los alcances y los modos de su participación en las acciones lideradas por Calfucurá. Q ueda asimismo pendiente un análisis de la política estatal hacia los indígenas que no debe sobreestimar en nuestra opinión el carácter unificado y consolidado del poder del estado, para atender a la complejidad y ambigüedad que asumieron, en los escenarios locales, los alineamientos políticos intra e interétnicos. 
Ingrid deJ ong

\section{Referencias bibliográficas}

Avendaño, Santiago. Memorias del ex cautivo Santiago Avendaño. Buenos Aires: El Elefante Blanco, 1999.

Bandieri, Susana. "Entre lo micro y lo macro: la historia regional. Síntesis de una experiencia". Entrepasados, no 11, 1996:71-100.

Barros, Álvaro [1872]. Fronteras y Territorios Federales de las Pampas del Sur. Buenos Aires: Solar, Hachette, 1975.

Bechis, Martha. "Los lideratos políticos en el área araucano-pampeana en el siglo XIX: ¿autoridad o poder?". I Congreso Internacional de Etnohistoria. Buenos Aires: Universidad de Buenos Aires, 1989.

- - . "Fuerzas indígenas en la política criolla del siglo XIX", en: N. Goldman y R. Salvatore, comps., Caudillismos rioplatenses. Nuevas miradas a un viejo problema. Buenos Aires: EUDEBA, 1998:293317.

-_- "La vida social de las biografías: el caso de la biografía de Juan Calfucurá, 'líder total' de una sociedad sin estado", en: R. Sautú, comp., El método biográfico: la reconstrucción de la sociedad a partir de los testimonios de los actores sociales. Buenos Aires: Editorial de la U niversidad de Belgrano, 1999:206-211.

-_- "La O rganización Nacional y las tribus pampeanas durante el siglo XIX", en: A. Escobar O hmstede, Romana Falcón y Raymond Buve, comps., Pueblos, comunidades y municipios frente a los proyectos modernizadores en América Latina, siglo XIX. CEDLA Latin America Studies (CLAS) series, no 88. Colegio de San Luis, México, Centro de Estudios y Documentación Latinoamericanos, U niversidad de Leiden, 2002:83-105.

Boccara, Guillaume. "Fronteras, mestizaje y etnogénesis en las Américas", en: R. Mandrini y C. Paz, comps., Las fronteras hispanocriollas del mundo indígena latinoamericano en los siglos XVIII y XIX. Neuquén: Instituto de Estudios Histórico Sociales, CEH iR, Universidad Nacional del Sur, 2003:63-108.

de Jong, Ingrid. "Acuerdos y desacuerdos: política estatal e indígenas en la frontera bonaerense (1856-1866)", en: R. Mandrini, A. Escobar O hmstede y Sara O rtelli, eds., Sociedades en M ovimiento. 
Los pueblos indígenas de América Latina en el siglo XIX. Tandil: Instituto de Estudios Histórico Sociales, 2007a:47-62.

-_- "Políticas indígenas y estatales en Pampa y Patagonia (18501880)". Hábitus, Vol. 5, no 2, julio-diciembre 2007b:301-331.

y Silvia Ratto. "La construcción de redes políticas indígenas en el área arauco-pampeana: la Confederación Indígena de Calfucurá (1830-1870)". Intersecciones en Antropología, no 9, 2008:241-260.

Delrio, Walter y Ana Ramos. “'Reunidos en Füta Trawün'. Agencias políticas y alianzas identitarias desde los parlamentos mapuchetehuelche". VIII Congreso Argentino de Antropología Social. Salta: U niversidad Nacional de Salta, septiembre de 2006.

Guevara, Tomás. Ultimas familias y costumbres araucanas. Santiago de Chile: Imprenta Barcelona, 1913.

Hux, Meinrado. Coliqueo el indio amigo de Los Toldos. Buenos Aires: Eudeba, 1980.

- _ Caciques Huilliches y Salineros. Buenos Aires: Marymar, 1991.

Jones, Kristine. "Calfucurá and Namuncurá: Nation Builders of the Pampas", en: J. Evell and W. Buzley Jones, The N ineteenth Century. Wilmington, D elaware: Scholarly Press Imprent, 1989:175-186.

- - . "W arfare, reorganization, and readaptation at the margins of Spanish rule: the southern margin (1573-1882)", en: F. Salomon and S. Schwartz, eds., The Cambridge history of the native peoples of the Americas, Vol. III. Cambridge: Cambridge University Press, 1999:138-187.

León Solís, Leonardo. "Alianzas militares entre los indios de Argentina y Chile. La rebelión araucana de 1867-1872". Nueva H istoria, Vol. 1, no 1, 1981:2-49.

-__ Maloqueros y conchavadores en Araucanía y las Pampas, 1700-1800. Temuco: Ediciones Universidad de la Frontera, Serie Quinto Centenario, 1991.

Levaggi, Abelardo. Paz en la frontera. Historia de las relaciones diplomáticas con las comunidades indígenas en la Argentina (siglos XVI-XIX). Buenos Aires: U niversidad del Museo Social Argentino, 2000. 
Ingrid deJ ong

Mandrini, Raúl. "Procesos de especialización regional en la economía indígena pampeana (siglos XVIII-XIX): el caso del suroeste bonaerense". Boletín Americanista, Vol. 32, n 41, 1991:113-136.

. "Los 'Araucanos' en las Pampas (c. 1700-1850)", en: G. Boccara, ed., Colonización, Resistencia y Mestizaje en las américas (siglos XVI-XX). Lima: IFEA/Q uito: Ediciones Abya Yala, 2002:237-257.

Morrone, Ariel. "La autoridad cacical en las sociedades indígenas de la región pampeana (siglos XVI-XIX). Algunas consideraciones historiográficas", en: Miradas al pasado desde Chivilcoy. Chivilcoy: CECH, 2004:746-763.

Musters, G eorge Chaworth [1871]. Vida entre los patagones. Buenos Aires: El Elefante Blanco, 1997.

Nacuzzi, Lidia. "Los cacicazgos duales en Pampa-Patagonia durante el siglo XVIII", en: Relaciones de la Sociedad Argentina de Antropología XIX, 1993-94:135-144.

- - I I Ientidades impuestas. Tehuelches, aucas y pampas en el norte de la Patagonia. Buenos Aires: Sociedad Argentina de Antropología, 1998.

- "Revisando y repensando el concepto de cacicazgo en las fronteras del sur de América (Pampa y Patagonia)". Revista Española de Antropología Americana, Vol. 38, no 2, 2008:75-95.

O szlak, O scar. La formación del Estado argentino. Buenos Aires: Ariel Historia, 2004.

Palermo, M iguel Ángel. "M apuches, pampas y mercados coloniales", en: Especial de Etnohistoria, CD-Rom. Facultad de Filosofía y Letras de la U niversidad de Buenos Aires, 1999.

N éspolo, Eugenia, M aría Laura Cutrera y Ariel M orrone. "El líder étnico, liderar y liderazgo. Los Yahatti, Lepin, Juan Manuel Cachul y Juan Catriel: hombres políticos en la frontera bonaerense". Ponencia presentada al Simposio "El liderazgo indígena en las fronteras americanas (siglo XVIII y XIX)". M useo Etnográfico de la UBA, 2 y 3 de agosto de 2007.

Pérez, Pilar. "Historiadores e Historias de Juan Calfucurá". Mundo Agrario, no 15, 2do. semestre 2007, www.mundoagrario.unlp.edu.ar. 
Pérez Zavala, Graciana. "La política interétnica de los ranqueles durante la segunda mitad del siglo XIX". Quinto Sol. Revista de Historia Regional, № 11, 2007:61-89.

Pinto Rodríguez, Jorge (ed.) Araucanía y Pampas. U n mundo fronterizo en América del Sur. Temuco: Ediciones U niversidad de la Frontera, 1996:11-46.

Raone, Juan Mario. "Los indígenas del Neuquén en la época de la campaña del General Roca". Separata del Congreso Nacional de Historia sobre la Conquista del Desierto (Gral. Roca, 1979). Buenos Aires: Academia Nacional de la Historia, 1985:217-233.

Ratto, Silvia. "Cuando las fronteras se diluyen. Las formas de interrelación blanco-indias en el sur bonaerense", en: R. M andrini y C. Paz, comps., Las fronteras hispanocriollas del mundo indígena latinoamericano en los siglos XVIII y XIX. Neuquén: Instituto de Estudios H istórico Sociales, CEH iR, UN del Sur, 2003:199-232.

-_- "Ni unitarios ni rosistas. Estrategias políticas interétnicas en Buenos Aires (1852-1857)". Estudios de Historia, Vol. 13, no 2, UNESP, 2006:1-33.

Tamagnini, Marcela, Ernesto Olmedo y Graciana Pérez Zavala. "Alianzas, intrigas y conflictos en la Frontera Sur, Río Cuarto (18521861)". Ponencia presentada en II Jornadas Espacio, Memoria e Identidad, Facultad de H umanidades y Artes. U niversidad N acional de Rosario, 2002.

- y G raciana Pérez Zavala. “Los ranqueles en la década de 1870: los caciques principales frente a los indios de la 'orilla'". Ponencia presentada al Simposio "El liderazgo indígena en las fronteras americanas (siglo XVIII y XIX)". M useo Etnográfico de la UBA, 2 y 3 de agosto de 2007.

Varela, Gladys y Luz María Font. “La erradicación indígena y el nuevo poblamiento en el noroeste neuquino", en: J. Pinto Rodríguez, ed., Araucanía y Pampas. Un mundo fronterizo en América del Sur. Temuco: Ediciones U niversidad de la Frontera, 1996:201-211.

Vezub, Julio. "Valentín Saygüeque y la 'Gobernación Indígena de las Manzanas'. Poder y etnicidad en Patagonia noroccidental (1860-1881)". Tesis de Doctorado en Historia. Tandil: Facultad de Ciencias Humanas, U NCPBA, 2005. 
Ingrid deJ ong

Villar, Daniel y Juan Francisco Jiménez. "La tempestad de la guerra. Conflictos indígenas y circuitos de intercambio. Elementos para una periodización (Araucanía y las Pampas, 1780-1840)", en: R. M andrini y C. Paz, comps., Las fronteras hispanocriollas del mundo indígena latinoamericano en los siglos XVIII y XIX. Neuquén: Instituto de Estudios Histórico Sociales, CEH iR, U N del Sur, 2003:123-172.

Zeballos, Estanislao [1878]. La conquista de 15.000 leguas. Buenos Aires: Solar Hachette, 1958.

\section{Resumen}

Analizamos en este trabajo las transformaciones de las relaciones internas al campo político indígena en las Pampas y Norpatagonia durante las últimas décadas de frontera. En este período, en que el estado avanza hacia su unificación política y consolidación institucional, las políticas estatales hacia el indígena muestran un perfil más unificado y dirigido a crear las condiciones para el avance de las fronteras. La política de tratados de paz, extendida prácticamente a la totalidad del mapa indígena, constituirá uno de los principales instrumentos por los cuales el estado intentará canalizar y ordenar sus vínculos con diferentes caciques y grupos. Nuestro interés se dirige a identificar los probables condicionamientos e influencias de esta política hacia los indígenas en la conformación, fortalecimiento y/o debilitamiento de las alianzas políticas. Apuntamos específicamente a reconstruir dentro de este contexto el proceso seguido por el liderazgo del cacique Calfucurá, con el objeto de identificar el impacto de las intervenciones estatales sobre el alcance de su convocatoria política a lo largo del período.

Palabras clave: Indígenas, Estado, tratados de paz, Pampa, Calfucurá.

The building and dismantling of a confederation: Calfucura's leadership during the national organization period

\section{Summary}

In this paper, transformations of internal links within the indigenous political field are explored, focusing on the last decades of the frontier. This period, in which the state progresses towards its political unification and institutional consolidation, state policies regarding 
Indian people show a more unified profile and aim to create the conditions necessary for the frontiers advance. The peace treaties policy, extended to almost the whole indigenous map, will be one of the devices through the state will attempt to canalize and to order its relations with different chiefs and groups. O ur interest attempts to identify the probable conditionings and influences of this policy on the indigenous population at the conformation, strengthening and weakening of their political alliances. We intend specifically to reconstruct - within this context- the process of the Calfucurá's leadership, to identify the impact of state interventions over the extent of his political summoning capacity during this period.

Key words: Indians, state, peace treaties, Pampa, Calfucurá.

Recibido: 08/07/08; aceptado: 11/09/2008. 